\title{
ANALISIS KEPUASAN MAHASISWA TERHADAP PELAYANAN PERPUSTAKAAN (STUDI KASUS PERPUSTAKAAN TI ISTN)
}

\author{
Erika \\ Prodi Teknik Industri Institute Sains Dan Teknologi Nasional \\ Er1k4_ye2n1@yahoo.co.id
}

\begin{abstract}
ABSTRAK
Tingkat kesuksesan perusahaan jasa dapat diukur dari seberapa besar tingkat kepuasan pelanggan terhadap pelayanan yang diberikan. Kepuasan merupakan gap yang terjadi antara persepsi dan harapan pelanggan. Perpustakaan merupakan salah satu lembaga penyedia jasa yang vital dalam dunia pendidikan, begitu pula dengan Perpustakaan Teknik Industri ISTN. Pada penelitian ini fokus analisis adalah pada fasilitas peminjaman buku yang diberikan kepada mahasiswa. Untuk melihat sistem kualitas jasa pada sistem perpustakaan digunakan dimensi kualitas jasa dalam "Assessment of Library Service Quality", serta dengan menggunakan Dimensi Kualitas Jasa dari Bery \& Parasuraman. Dari perhitungan gap diperoleh hasil bahwa semua dimensi bernilai negatif yang berarti persepsi pelanggan tidak sesuai dengan harapan mereka. Namun dari plot rata-rata dimensi pada diagram dua dimensi 7 variabel masuk pada kuadra ke Tiga yang berarti konsumen sudah puas dengan pelayanan Perpustakaan TI ISTN.
\end{abstract}

Kata Kunci :

Perpustakaan, Assessment of Library Service Quality, Dimensi Kualitas Jasa Bery \& Parasuraman

\section{PENDAHULUAN}

Suatu perusahan baik itu dibidang indutri ataupun jasa hubungnganya sangat dekat dengan konsumen, karena salah satu dari karakteristik perusahaan jasa adalah berhubungan dengan konsumen secara intensif. Untuk itu tingkat kesuksesan perusahaan jasa dapat diukur dari seberapa besar tingkat kepuasan pelanggan terhadap pelayanan yang diberikan. Rasa tidak puas akan dapat menyebabkan pelanggan berpindah pada produsen lain. Kepuasan merupakan gap yang terjadi antara persepsi dan harapan pelanggan. Persepsi adalah penilaian pelanggan terhadap suatu produk atau jasa, sedangkan harapan adalah harapan atau keinginan pelanggan akan produk atau jasa yang dirasakan.

Perpustakaan sebagai salah satu organisasi yang menyediakan pelayanan untuk para mahasiswa maka dari itu haru memberikan pelayanan yang baik bagi para mahasiswa. Upaya untuk meningkatkan kualitas pelayanan harus dilakukan di seluruh aspek, baik aspek Sumber Daya Manusia (SDM) maupun aspek teknis. Perpustakaan seharusnya menjadi motor untuk melakukan pembelajaran, baik secara formal maupun non formal. Selain itu perpustakaan juga harus bisa mendorong kemajuan dunia pendidikan. Untuk mencapai tujuan tersebut dibutuhkan manajemen pengelolaan yang baik. Secara formal perpustakaan bisa lebih meningkatkan kreatifitasnya dalam menyediakan informasi. Untuk melihat apakah perpustakan TI ISTN sudah memberikan kualitas pelayanan yang baik untuk mahasiswa maka dilakukan penelitian untuk mengetahui tingkat kualitas jasa yang diberikan Perpustakaan TI ISTN dalam memberikan layanan kepada pelanggannya.

\section{DASAR TEORI}

Dalam "Assessment of Library Service Quality", dimensi kualitas jasa secara garis besar dibagi dalam 3 kategori, yaitu:

a. Pengaruh pelayanan (Affect of Service)

b. Pengendalian informasi (information control)

c. Perpustakaan sebagai tempat (library as place)

Cook, C. dan Heath, F. M. (2001) juga membagi dimensi kualitas jasa pada sistem perpustakan menjadi beberapa kategori, yaitu:

a. Pengaruh pelayanan (Affect of Service) 
Dimensi ini meliputi dimensi empati, tanggung jawab (responsiveness), dan Assurance.

b. Reliability

c. Library as Place

Dimensi ini meliputi utilisasi ruangan yang ada di perpustakaan (utilization space) dan perpustakaan sebagai symbol intelektualitas.

d. Self reliance

e. Comprehensive collections

f. Kemudahan akses

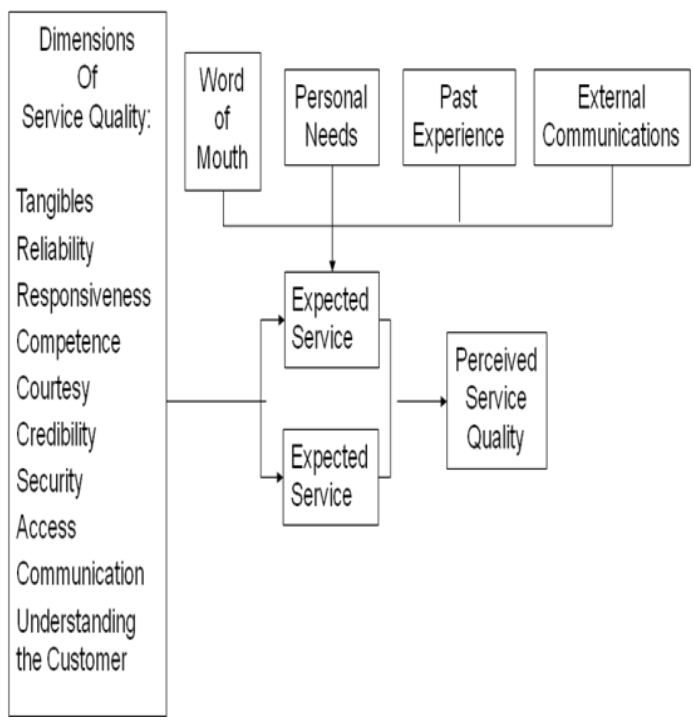

Gambar 1. Bagan The Customers View of Service Quality

Uji reliabilitas dan validitas kuesioner :

a. Uji reliabilitas

Reliabilitas adalah alat untuk mengukur suatu kuesioner yang merupakan indikator dari variabel. Suatu pertanyaan yang dapat dipertanggung jawabkan dapat diandalkan atau dapat dipertanggung jawabkan jawaban seseorang terhadap yang dikonfirmasi atau stabil dari waktu ke waktu.

Pengukuran reliabilitas dapat dilakukan dengan dua cara, yaitu:

- Pengukuran berulang atau pengukuran ulang

Apapun yang akan disodori pertanyaan yang sama pada waktu yang berbeda, dan kemudian dilihat apakah ia tetap disetujui dengan pertanyaan.

- Satu tembakan atau pengukuran sekali saja

Pengukurannya hanya sekali dan kemudian dilanjutkan dengan menjawab pertanyaan lain atau menghitung pertimbangan pertanyaan. SPSSmemberikan fasilitas untuk mengukur reliabilitas dengan uji statistik Cronbach Alpha $(\alpha)$. Beberapa variabel yang dapat diandalkan jika memberikan nilai Cronbach Alpha> 0,60 (Nunnally, 1967).

b. Uji validitas

Uji validitas digunakan untuk mengukur sah atau valid tidaknya suatu kuesioner. Pertanyaan yang diajukan valid jika pertanyaan yang diajukan pada pertanyaan yang diajukan akan diajukan oleh pertanyaan tersebut.

Mengukur validitas dapat dilakukan dengan tiga cara, yaitu:

- Melakukan pertanyaan antar skor butir pertanyaan dengan total skor variabel

- melakukan perubahan bivariat antara masing-masing skor indikator dengan skor total

- Uji dengan Confimatory Factor Analysis (CFA)

\section{METODE DAN TEKNIK PENGUKURAN}

\section{A. Pembuatan Instrumen Survey}

Langkah-langkah yang dilakukan dalam membuat instrumen survey antara lain :

a. Menentukan Customer Attribute.

Customer attribute yang digunakan pada penelitian ini merupakan kombinasi dari dimensi kualitas jasa yang dikembangkan Parasuraman dan Cook ditambah dengan tiga dimensi pokok. Ada 13 dimensi kualitas yang digunakan, yaitu: faster, cheaper, better, library as place, collection dan access, assurance, reliability.

\section{b. daya tanggap, persepsi dan empati.}

a. Membuat Variabel Tabel Operasi

b. Buat pertanyaan untuk mengukur atribut. Untuk mengukur ini, Alat Survei akan dibuat dalam bentuk kuesioner.

Ada dua jenis profil:

1. Kuesioner persepsi pelanggan berisi peringkat pelanggan berdasarkan kriteria kualitas yang disediakan oleh perpustakaan IT ISTN.

2. Kuesioner harapan pelanggan berisi harapan pelanggan mengenai kualitas layanan di perpustakaan ISTN.

otzyvchivost ', oshchutimost' i empatiya. 
a. Sozdaniye peremennykh operatsionnykh

\begin{tabular}{|c|c|c|c|}
\hline Indikator & Persepsi & Harapan & Gap \\
\hline Faster1 & 2,65 & 4,65 & -2 \\
\hline Faster2 & 3,65 & 4,5 & $-0,85$ \\
\hline Better1 & 2,7 & 4,35 & $-1,65$ \\
\hline Cheaper1 & 2,9 & 3,9 & -1 \\
\hline Cheaper2 & 3,15 & 3,55 & $-0,4$ \\
\hline $\begin{array}{l}\text { Library as Place } \\
\text { Space1 }\end{array}$ & 3,65 & 4,55 & $-0,9$ \\
\hline $\begin{array}{l}\text { Library as Place } \\
\text { Space2 }\end{array}$ & 3,5 & 4,55 & $-1,05$ \\
\hline $\begin{array}{l}\text { Library as Place } \\
\text { Space3 }\end{array}$ & 2,75 & 4,65 & $-1,9$ \\
\hline $\begin{array}{l}\text { Library as Place } \\
\text { Space4 }\end{array}$ & 3,6 & 3,15 & 0,45 \\
\hline $\begin{array}{l}\text { Collection \& } \\
\text { Access1 }\end{array}$ & 2,85 & 4,75 & $-1,9$ \\
\hline $\begin{array}{l}\text { Collection \& } \\
\text { Access } 2\end{array}$ & 2,25 & 4,75 & $-2,5$ \\
\hline $\begin{array}{l}\text { Collection \& } \\
\text { Access3 }\end{array}$ & 3 & 4,55 & $-1,55$ \\
\hline $\begin{array}{l}\text { Collection \& } \\
\text { Access4 }\end{array}$ & 2,65 & 4,1 & $-1,45$ \\
\hline $\begin{array}{l}\text { Collection \& } \\
\text { Access5 }\end{array}$ & 3,65 & 4,6 & $-0,95$ \\
\hline $\begin{array}{l}\text { Collection \& } \\
\text { Access6 }\end{array}$ & 3,9 & 4 & $-0,1$ \\
\hline $\begin{array}{l}\text { Collection \& } \\
\text { Access7 }\end{array}$ & 3,2 & 3,45 & $-0,25$ \\
\hline Assurance1 & 3,5 & 4,45 & $-0,95$ \\
\hline Assurance2 & 3,5 & 4,45 & $-0,95$ \\
\hline Assurance3 & 3,05 & 3,9 & $-0,85$ \\
\hline Responsiveness 1 & 3,65 & 4,05 & $-0,4$ \\
\hline Responsiveness2 & 2,95 & 4,3 & $-1,35$ \\
\hline Responsiveness 3 & 3,65 & 4,25 & $-0,6$ \\
\hline Tangibles1 & 3,55 & 4,55 & -1 \\
\hline Tangibles2 & 3,1 & 4,6 & $-1,5$ \\
\hline Tangibles3 & 3,75 & 4,25 & $-0,5$ \\
\hline Tangibles4 & 3,45 & 4,55 & $-1,1$ \\
\hline Tangibles5 & 2,95 & 4,35 & $-1,4$ \\
\hline Tangibles6 & 3,75 & 4,15 & $-0,4$ \\
\hline Tangibles7 & 1,6 & 4,2 & $-2,6$ \\
\hline Tangibles8 & 1,75 & 4 & $-2,25$ \\
\hline Empathy1 & 3,55 & 4,2 & $-0,65$ \\
\hline Empathy2 & 2,9 & 4,05 & $-1,15$ \\
\hline Empathy3 & 3,55 & 4,05 & $-0,5$ \\
\hline Empathy4 & 2,9 & 4,55 & $-1,65$ \\
\hline Reliability 1 & 2,95 & 4,35 & $-1,4$ \\
\hline Reliability2 & 2,9 & 4,45 & $-1,55$ \\
\hline
\end{tabular}

tablits

b. Sdelayte voprosy, atribut chtoby izmerit '. Chtoby izmerit 'eto, Instrumen Obzora budet sdelan v forme voprosnika.

Sushchestvuyet dva vida anket:
1. Oprosnik po vospriyatiyu kliyentov soderzhit otsenki kliyentov po kriteriyam kachestva, predostavlyayemym IT-bibliotekoy ISTN.

2. Oprosnik ozhidaniy kliyentov soderzhit ozhidaniya kliyentov $\mathrm{v}$ otnoshenii kachestva obsluzhivaniya v IT-biblioteke ITB.

\section{Penentuan Responden}

Pada penelitian tentang kualitas jasa di perpustakan TI ISTN digunakan responden yang betul-betul paham dan menggunakan jasa perpustakaan. Responden yang dipilih adalah mahasiswa ISTN baik mahasiswa lama maupun mahasiswa.

\section{B. Menentukan Jumlah Sampel}

Jumlah sampel penelitian ini ditentukan dengan menggunakan rumus

$$
\text { Jumlah sampel }=\frac{N}{1+N \cdot e^{2}}
$$

Rumus tersebut digunakan karena jumlah mahasiswa ISTN yang menggunakan fasilitas Perpustakaan TI ISTN dapat didefinisikan.

Dengan $\mathrm{N}=4300$ dan $\mathrm{e}=0,01$ diperoleh jumlah sample :

$$
\underset{\text { Tumbel }}{\text { J. Gap Indikator }}=\frac{244}{1+244 \cdot 0,0 \mathbf{1}^{\mathbf{2}}}=10
$$

Dalam penelitian ini digunakan sebanyak 20 sampel. Dari 20 sampel ini dilakukan uji reliabilitas dan validitas, untuk meyakinkan bahwa alat ukur dan pertanyaan yang dibuat sudah bagus. Hal ini dilakukan karena pada dasarnya data yang digunakan kurang, sehingga untuk menghindari kesalahan uji reliabilitas dan validitas, dilakukan pada 5 data awal dan 20 data akhir.

\section{HASIL DAN PEMBAHASAN}

\section{A. Test Instrumen}

Pada test instrumen ini ada beberapa hal yang tidak dilakukan sesuai dengan prosedur yang seharusnya. Hal ini terjadi karena keterbatasan waktu dan biaya. Test yang dilakukan antara lain :

1. Mencoba pertanyaan pada 3 orang untuk mengetahui apakah pertanyaan sudah dipahami atau belum. Pada tes pertama ini dibuat beberapa perbaikan untuk pertanyaan pada beberapa indikator.

2. melakukan uji validitas dan reliabilitas. Pengujian ini dilakukan sebanyak 2 kali untuk data yang terkumpul benar-benar reliabel dan valid. Pengujian ini dilakukan pada 5 orang 
responden, dan pengolahan data menggunakan perangkat lunak SPSS.

\section{A. Mengolah Data}

Tahapan pada saat pengolahan data antara lain: 1. Mencari rata-rata pada setiap indikator dan variabel yang diterima.

2. Rangkuman atau matriks gabungan dan harapan untuk setiap variabel dan indikator yang diterima. Selain itu juga dihitung kesenjangan antara persepsi dan harapan.

Dari Tabel 1 dapat dilihat semua indikator bernilai negatif. Layanan ini diberikan oleh Perpustakaan TI ISTN masih jauh dari harapan pelanggan.

Tabel 2. Gap Variabel

\begin{tabular}{|c|c|c|c|c|}
\hline $\begin{array}{c}\text { Kod } \\
\mathrm{e}\end{array}$ & Dimensi & $\begin{array}{c}\text { Persep } \\
\text { si } \\
\end{array}$ & $\begin{array}{c}\text { Harap } \\
\text { an }\end{array}$ & $\begin{array}{c}\mathrm{Ga} \\
\mathrm{p}\end{array}$ \\
\hline $\mathrm{A}$ & Faster & 3,15 & 4.58 & $\begin{array}{c}- \\
1,4 \\
3\end{array}$ \\
\hline B & Better & 2,70 & 4,35 & $\begin{array}{c}- \\
1,6 \\
5\end{array}$ \\
\hline $\mathrm{C}$ & Cheaper & 3,03 & 3,73 & $\begin{array}{c}- \\
0,7 \\
0\end{array}$ \\
\hline $\mathrm{D}$ & $\begin{array}{l}\text { Library as } \\
\text { Place Space }\end{array}$ & 3,38 & 4,23 & $\begin{array}{c}- \\
0,8 \\
5\end{array}$ \\
\hline$E$ & $\begin{array}{l}\text { Collection \& } \\
\text { Access }\end{array}$ & 3,07 & 4,31 & $\begin{array}{c}- \\
1,2 \\
4\end{array}$ \\
\hline $\mathrm{F}$ & Assurance & 3,35 & 4,27 & $\begin{array}{c}- \\
0,9 \\
2\end{array}$ \\
\hline $\mathrm{G}$ & $\begin{array}{l}\text { Responsiven } \\
\text { ess }\end{array}$ & 3,42 & 4,20 & $\begin{array}{c} \\
0,7 \\
8\end{array}$ \\
\hline $\mathrm{H}$ & Tangibles & 2,99 & 4,33 & $\begin{array}{c}- \\
1,3 \\
4\end{array}$ \\
\hline I & Empathy & 3,23 & 4,21 & $\begin{array}{c}- \\
0,9 \\
9\end{array}$ \\
\hline $\mathbf{J}$ & Reliability & 2,93 & 4,40 & $\begin{array}{c} \\
1,4 \\
8 \\
\end{array}$ \\
\hline
\end{tabular}

Dari Tabel 2 dapat dilihat semua variabel bernilai negatif. Hal ini disampaikan bahwa layanan yang diberikan oleh Perpustakaan TI
ISTN masih jauh dari harapan pelanggan (mahasiswa S2 TI ISTN).

1. Diagram Dua Dimensi

Diagram dua dimensi ini mendukung untuk menentukan posisi dan harapan pelanggan pada setiap variabel yang disetujui. Diagram ini terdiri dari 4 kwadran dengan keterangan sebagai berikut (urutan dari pojok kiri bawah dan memutar searah jarum jam):

a. Kwadran 1 menunjukkan persepsi dan harapan sama-sama rendah, yang berarti variabel ini tidak dirasa penting oleh pelanggan atau produsen.

b. Kwadran 2 menunjukkan daerah pelanggan tidak puas sehingga perlu diperbaiki.

c. Kwadran 3 menunjukkan daerah puas untuk pelanggan.

d. Kwadran 4 menunjukkan daerah dimana konsumen sangat puas namun sebenarnya konsumen tidak mengharapkan itu.

Dari hasil, grafik, 2 dimensi, diperoleh, hasil,,,,,,,,,,,,,,,. Densi ketiga ini antara lain Densi B, Densi H dan Densi J. Sementara 7 densi yang lain terletak pada kuadran 2 yang berkaitan dengan pelanggan telah puas dengan layanan kesepuluh dimensionalali tersebut, hal ini berarti diananan yanananga palayanan palayanaka palayanan palayanaka sudanan sudanan pelanggan. 


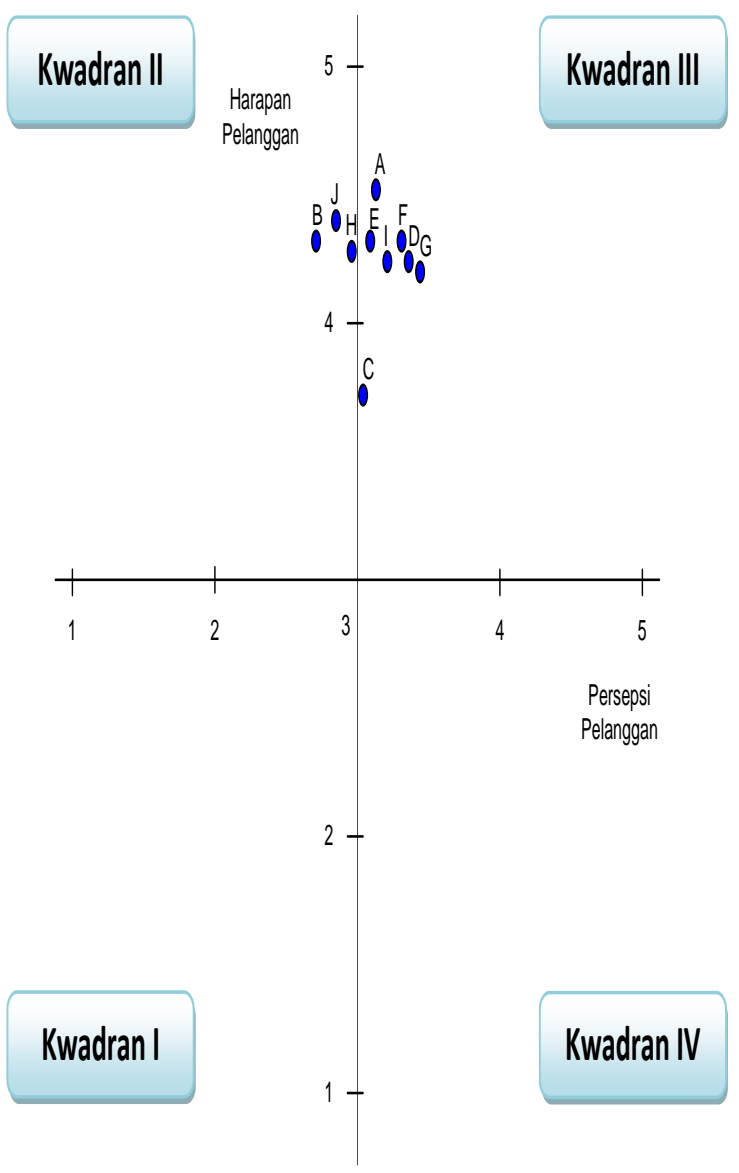

Gambar 2. Grafik Dua Dimensi

\section{B. KESIMPULAN}

1. Dari perhitungan gap diperoleh hasil bahwa semua dimensi bernilai negatif yang berarti persepsi pelanggan tidak sesuai dengan harapan mereka. Namun dari plot rata-rata dimensi pada diagram dua dimensi 7 variabel masuk pada kuadran 3 yang berarti konsumen sudah puas dengan pelayanan Perpustakaan TI ISTN.

2. Perbaikan yang dapat diusulkan untuk indikator yang masuk pada kuadran 2 antara lain :

a. Better :

- Melakukan trainning kepada staf perpustakaan agar dapat lebih sigap dalam memberikan layanan.

b. Tangible :

- Memperbaiki fasilitas yang digunakan (komputer lebih up date, diberi fasilitas tambahan contoh kertas, alat tulis dan form untuk mempermudah peminjaman serta melengkapi dengan sarana serta prasarana seperti tempat sholat dan kamar mandi.

c. Reliability
- Menambah kemampuan pegawai agar lebih cekatan dalam menyelesaikan masalah pelanggan.

- Ada kontrol dari pimpinan dan dokumentasi yang bagus agar pegawai dapat menyediakan buku yang dipesan dengan tepat waktu.

\section{DAFTAR PUSTAKA}

Cook, C dan Heath, F. M., User's Perception of Library Service Quality: A Libqual + Qualitative StudI, 2001, University of Illinois.

Cook, C., Heath, F. M., dan Thompson. B., User' Hierarchical Perspectives on Library Service Quality: A" Libqual +" Study, 2001, University of Illinois.

Ghozali, I., Analisis Multivariat dengan Program SPSS.Semarang, 2005, Badan Penerbit Universitas Diponegoro.

Libqual report engineering,doc. Assessment of Library Service Quality: Library and Information Service Centre of Sirindhorn International Institute of Technology.

Nimsomboon, N. dan Nagata, H., Assessment of Library Service Quality at Thammasat University Library System, 2003, Thailand: Department of Library Science Faculty of Liberal Arts Thammasat University.

Parasuraman, A. et al., Delivering Quality Service - Balancing Customer Perception and Expectation, 1990, London: Collier Macmillan Publisher. 